\title{
Creating a whole institution approach to in-service training in sexual and reproductive health in Uganda
}

\author{
Jonathan Graffy, ${ }^{1}$ Sarah J Capewell, ${ }^{2}$ Clare Goodhart, ${ }^{3}$ \\ Birungi Mutahunga Rwamatware ${ }^{4}$
}

\begin{abstract}
${ }^{1}$ Senior Clinical Research Fellow, Primary Care Unit, Department of Public Health and Primary Care, University of Cambridge, Institute of Public Health, Cambridge, UK

${ }^{2}$ General Practitioner, Greater Glasgow and Clyde, and formerly Bwindi Community Hospital, Kanungu, Uganda ${ }^{3}$ General Practitioner, Lensfield Medical Practice, Cambridge, UK ${ }^{4}$ Executive Director, Bwindi Community Hospital, Kanungu, Uganda
\end{abstract}

\section{Correspondence to}

Dr Jonathan Graffy, Primary Care Unit, Department of Public Health and Primary Care, University of Cambridge, Institute of Public Health, Robinson Way, Cambridge CB2 OSR, UK; jpg43@medschl.cam. ac.uk

Received 5 May 2014 Revised 28 July 2015 Accepted 20 August 2015 Published Online First 10 September 2015

\section{CrossMark}

\footnotetext{
To cite: Graffy J, Capewell SJ, Goodhart C, et al. J Fam Plann Reprod Health Care 2016:42:52-58.
}

\section{ABSTRACT}

Background Uganda has one of the world's highest fertility rates, and high unmet need for family planning, even when clients have contact with health facilities. Misconceptions about contraceptive side effects and inadequate training for healthcare workers contribute to this. Aim To develop and evaluate in-service training for family planning, across a whole institution.

Design Course evaluation. Impact on services.

Methods Following a needs assessment, two courses were developed, adapting WHO's Training Resource Package for Family Planning. All staff were offered level 1 training (five $1 \mathrm{~h}$ sessions). The $30 \mathrm{~h}$ level 2 course aimed to train clinical staff to certificate level; assessed by written exam, consultation skills and presentations. Quantitative evaluation assessed changes in pre-course and post-course knowledge and confidence scores. Participant feedback was analysed thematically.

Results Of the hospital's 76 clinical staff, 44 attended some training. Of these, 21 attended and 19 completed level 2. Mean knowledge scores increased from 15.9 (SD 4.5) to 20.8 (SD 3.1)/26 (95\% Cl 4.9 (2.5-7.2)). Confidence rose from 8.1 (SD 1.5) to 9.5 (SD 0.5) $(95 \% \mathrm{Cl} 1.4$ (0.7-2.2)). Nine were accredited to fit intrauterine devices and implants, and three just implants. Screening for unmet need is being introduced and outreach work aims to overcome barriers to adoption of family planning.

Conclusions Brief in-service training improves health workers' knowledge and skills, corrects misconceptions and increases the priority given to family planning. When aligned to local need and the culture of the institution, training can prompt moves to address unmet need for family planning

\section{INTRODUCTION}

Uganda's population of 37.6 million is growing by $3.3 \%$ annually, a challenge to

\section{Key message points}

- Unwanted pregnancies in Uganda impact many areas of health. Identifying and addressing unmet need for contraception is the responsibility of all health workers.

- Offering training across a whole institution was well received, gave staff the confidence and skills to discuss the topic, and stimulated service change.

- Ugandan health workers with basic nurse training can provide a high standard of counselling and contraceptive provision after $30 \mathrm{~h}$ of interactive teaching.

the future health and development of the country. ${ }^{1}$ On average, Ugandan women have 5.9 children, and the maternal mortality ratio is stubbornly high (438/ $100000)$, partly attributable to illegal abortions. ${ }^{2}$ There is high unmet need for family planning, and $34 \%$ of married women who do not want a child report they are not using contraception. ${ }^{2}$ Despite this, demand for family planning is limited by widespread fears of side effects, ${ }^{3}$ over-reliance on breast feeding beyond 6 months for contraception, male attitudes and the social unacceptability of unmarried women using contraception. ${ }^{45}$

Most family planning in Uganda is provided by non-governmental organisations (NGOs) through vertical programmes, but government policy advocates a more horizontal system of delivery, integrating family planning services into all health facilities. $^{6-8}$ Opportunities to discuss family planning are missed: only $28 \%$ of women treated for miscarriage and 
abortion, and only $16 \%$ of women giving birth in a health facility receive contraception advice before discharge. ${ }^{2}$

So why are health workers not discussing family planning with their clients? We know from the Cochrane review on integrating family planning into other health services that advice from generic health workers is crucial. ${ }^{910}$ Although sexual and reproductive health is included within the basic training of all health workers, post-basic training is fragmented, ${ }^{11}$ and often takes staff away from their already overstretched clinics. When they return to their workplace, trainees may have little scope to make use of their learning.

We report on the development and evaluation of in-service training for Ugandan health workers, piloted within a rural hospital setting. This aimed to equip clinical staff with the knowledge, confidence and skills to offer family planning counselling and, where appropriate, interventions. The overall aim of this integrated approach was to increase the number of health encounters at which family planning was discussed and subsequently provided.

\section{METHOD}

\section{Context and course development}

Bwindi Community Hospital is a private, not for profit, 112-bed facility with 76 clinical staff providing comprehensive healthcare to a population of over 100000 people in rural south-west Uganda. A situational analysis was conducted by a UK general practitioner, working at the hospital as a long-term volunteer (SJC). In the previous year, 2612 episodes of family planning care had been provided (injectable: 66\%; combined pill: 20\%; intrauterine device (IUD): 8\%; condoms: 6\%). Fourteen clinical staff in different departments were asked about their roles in family planning and challenges they faced in discussing this with clients. This identified that training was indeed needed, covering attitudes towards family planning, potential side effects and practical skills. Two levels of training were then devised, the first offering generic awareness for all hospital staff, and the second, in-depth training for clinical staff who might provide family planning.

\section{Level $\mathbf{1}$ training for all staff}

These sessions were led by a Ugandan diploma-level nurse and two UK general practitioners over five, hour-long, morning sessions before normal duties began. All staff were invited, although some were unable to attend if covering wards, on night duty, had days off or were travelling to outreach clinics.

The first two sessions, which non-clinical staff also attended, examined national and local data showing the detrimental impact of unwanted pregnancies and over-large families on many aspects of health. Discussion covered the level of unmet need and opportunities to promote family planning. The following three sessions aimed to improve clinicians' knowledge and change attitudes towards commonly available contraceptive methods (injection, implant, IUD and combined oral contraceptive), but also covered other options. One session involved role plays on how to raise the topic (Box 1). Because fears of side effects had previously been identified as limiting uptake of contraception, time was devoted to brainstorming the myths and genuine side effects that might arise with each method. ${ }^{3}$ Sessions involved interactive teaching methods, using WHO resources and a family planning counselling flipchart from the Ugandan Ministry of Health (Box 2). ${ }^{12} 13$

\section{Level 2 training for clinicians providing family planning}

This seminar-based course provided $30 \mathrm{~h}$ of in-service training over 1 week, designed to equip clinical staff with knowledge, counselling and practical skills to extend the reach of the hospital's sexual and reproductive health services. Trainees were encouraged to undertake online pre-course learning. ${ }^{14}$ The interactive sessions included presentations based on the WHO Training Resource Package for Family Planning, ${ }^{12}$ external speakers, small group work and role-play counselling sessions. Examples of contraceptives were available and trainees observed the insertion and removal of implants and IUDs on video and live patients before practising with anatomical models. One morning was spent on cervical screening and the syndromic management of sexually transmitted infections because of their relevance to delivering contraceptive services. ${ }^{6}$

Trainees were assessed on their performance in case discussions, role play, mock community education talks, and a $1 \mathrm{~h}$ multiple choice question (MCQ) examination. If successful, they were awarded the course certificate and invited to arrange practical supervision with the lead family planning nurse for accreditation in the insertion and removal of implants and IUDs. The course was delivered twice, the second time after an interval of 6 months.

\section{Box 1 Scenarios for role play exercises}

- Young man attending with genital warts: Not yet married and does not see the relevance of family planning, but may respond to a non-judgemental discussion of the importance of condoms

- Woman who has just had an obstructed labour with her fourth child: Discuss long-acting reversible or permanent contraception options with her.

- Mother of 2-year-old twins who have been admitted with malnutrition: Explore whether she currently has an unmet need for family planning and help her to address this 


\section{Box 2 Resources for family planning courses}

Training Resource Package for Family Planning (http:/l www.fptraining.org/about), $\mathrm{WHO}^{12}$

- Family Planning: A Global Handbook for Providers (http://www.fphandbook.org/), WHO handbook ${ }^{13}$

- Medical Eligibility Criteria (MEC) Wheel (WHO Department of Reproductive Health and Research and Johns Hopkins Bloomberg School of Public Health/ Center for Communication Programs Knowledge for Health Project 2011), one of these decision aids for each trainee

- Family Planning Counselling Tool (http://www.health. go.ug/docs/ucg_2010.pdf), Ugandan Ministry of Health, freely available in the local language

- Anatomical models for demonstration and practice: male and female anatomy, upper arms (implants), wombs (coils)

\section{Evaluation}

Trainees were asked to complete pre-course and postcourse questionnaires, including free text comments about how the training could be improved. The evaluation form asked about their current roles, past training in family planning and how often they discussed it with men and women. It included an eight-item assessment of confidence in discussing family planning and a short knowledge assessment, comprising 16 multiple choice and true/false questions, drawn from the WHO Training Resource Package. ${ }^{12}$ Mean precourse and post-course confidence and knowledge scores were analysed using paired sample t tests using SPSS (IBM Corp 2013).

Text was analysed thematically by a member of the research team who was not involved in course delivery. This involved transcribing and grouping the responses to develop categories and identify comments that illustrated the themes that emerged. Each session was also evaluated by the tutors.

\section{RESULTS}

\section{Participants}

Of the hospital's 76 clinical staff, 44 attended some training. Twenty-eight attended level 1 sessions, (along with 8 non-clinical staff for the two introductory sessions), while 21 undertook the level 2 course (13 nurses, 5 midwives, 2 public health workers and a nursing assistant).

The 44 clinical staff who took part (24 women, 20 men; median age 26) were asked how often they discussed family planning. Twenty-eight (64\%) did so with female patients at least once a week, whereas only 18 (41\%) did with male patients. Eleven reported some post-basic training in family planning, which ranged from clinical meetings at the hospital to courses in particular methods, such as IUDs or implants, whereas 27 only had this in their basic training, and 6 had no previous family planning training. Prior to this training, 30 of the 44 graded their confidence in advising about different aspects of family planning, reporting a mean score across all topics of 8.0 (SD 1.4) out of 10.

\section{Evaluation of level 1 sessions}

Participants liked the varied teaching methods. Brainstorming using flipcharts was described as 'refreshing', 'enabling people to think' and 'good for participation'. It allowed confident members of the small groups to share their knowledge, overseen by the facilitators who were able to correct misconceptions during the plenary. Role play was also seen as giving people confidence to discuss family planning options.

Time management emerged as an issue. Whilst some would have liked longer sessions, others had difficulty attending because of clinical commitments, so the facilitators repeated one session in the evening. In response to participants' suggestions, a clearer programme was drawn up, handouts on managing side effects were prepared, presentations were emailed to participants and flipcharts were left on display in the staff room for a week.

Commenting on the impact of the level 1 training, several said that they were more confident in discussing family planning, that it was useful to know when to avoid particular methods and how to manage side effects. Comparison with pre-course scores is problematic because these were unavailable for several who joined after the first session, but the mean postcourse confidence score across all the domains was 9.3 (SD 0.9) $(n=26)$. The topic with the lowest score was confidence in discussing family planning with male patients (8.8 (SD 2.1)/10). The issue of how to engage with men was raised during discussions and appeared to merit further attention, so a men's engagement meeting was organised after the course.

Reviewing the course, the tutors felt that participants had responded well to the interactive teaching methods, but that more use could have been made of the WHO counselling aids. Including non-clinicians for the first two sessions worked well, but these could have been amalgamated into a single introductory session for all staff.

\section{Evaluation of level 2 course}

In total, 21 clinical staff began one of the two level 2 courses; 2 withdrew because of other commitments, but re-joined the second course and 19 passed the final assessment. All trainees appeared to gain significant benefit, and their mean confidence rose from 8.1 (SD 1.5 ) to 9.5 (SD 0.5), 95\% CI 1.4 (0.7-2.2). Knowledge scores increased from a mean of 15.9 (SD 4.5) to 20.8 (SD 3.1)/26，95\% CI 4.9 (2.5-7.2). The session content and tutors' evaluations are shown in Table 1. 
In evaluating the level 2 course, trainees gave many positive comments. They liked the small group work, role play, anatomical models and chance to handle contraceptives. They appreciated having outside speakers on particular topics (the hospital surgeon: sterilisation; HIV expert patient: promoting condom use; health educator: how to give health talks). Although they had mainly experienced didactic teaching in the past, they engaged easily with the active learning methods.

Most participants commented that the course was the right length and appreciated the relatively fast pace of learning - had the course been longer they would not have been able to commit to it. Several, however, felt it was too intense. One nurse suggested it should be 'at least 2 weeks because it contained many things and we were rushing'. Others would have preferred half-day sessions, with time scheduled for the pre-course reading. Several said they hoped to use what they had learnt, sharing their knowledge with the community.

\section{Impact on services}

After the courses, nine trainees went on to become proficient in fitting both IUDs and implants, and three in implants. Paediatric nurses, who routinely witness the contribution of malnutrition to ill health, now offer counselling to parents of in-patient children, and fit implants when requested.

Screening questions to identify unmet need have been added to the clinical assessment forms used in consultations across the hospital. These were: Do you wish to have a child in the next two years? [If answered no] Which method of family planning are you (or your partner) using? Initial experience has suggested that they could open up a discussion on methods but that screening worked best when healthcare workers had time, that is, with in-patients and mothers waiting to deliver, but not so well in the busy outpatient department.

Another initiative was a meeting for men, organised at a local bar to discuss how to engage men in family planning and make services more accessible. Also a 20 min film was made with the paediatrician, hospital chaplain, a village health promoter and a patient with HIV talking about family planning in the local language. This is shown in outpatients, outreach clinics, and in local schools and churches. Several trainees also gave talks at these outreach meetings.

Table 1 Content and tutors' evaluation of level 2 course

\begin{tabular}{ll}
\hline Content & Tutors' comments \\
\hline Day 1: Fundamentals of contraception & This led to discussion about recent deaths from septic abortion and missed opportunities to \\
discuss contraception. & Lnmet need, consent and confidentiality \\
- Overview of methods and their efficacy & $\begin{array}{l}\text { disadvantages and efficacy of methods. } \\
\text { Participants struggled to remember physiology and explain rhythm method. Moon beads } \\
\text { - Physiology and natural methods }\end{array}$ \\
Anatomy and sterilisation & $\begin{array}{l}\text { Group work drawing anatomy did build on prior knowledge. Hospital surgeon's talk on } \\
\text { sterilisation was well received }\end{array}$
\end{tabular}

Day 2: Methods

- Injections

- Implants

- Intrauterine devices (IUDS)

- Oral contraceptives

Day 3: Contraceptive counselling

- Condoms, male and female

- Principles of counselling

- Counselling scenarios

Day 4: Sexual health/practical skills

- STI diagnosis and management

- Demonstrations of cervical cytology, implant insertion and removal, IUDs

Day 5: Reaching target groups

- Emergency contraception

- Adolescent-friendly services

- Preparing presentations for antenatal mothers, parents on paediatric ward, teenagers

- Final assessment (MCQ exam and course evaluation)
Intensive day with PowerPoint presentations about each method. Interspersing this with small group sessions using flipcharts, case discussion, MEC wheels, videos and practice with models helped maintain interest

An HIV 'expert patient' demonstrated the promotion and use of male condoms. Few had seen female condoms before.

Session based on WHO counselling tools.

Substantial time was given to role play, allowing participants to consolidate their knowledge of methods and side effects

Session based on Uganda guidelines for vaginal discharge, pelvic pain, genital ulcers and urethral discharge in men. Participants recreated algorithms using pre-prepared post-it notes. Quiz and case discussion on teenage STIs.

Parallel groups had case discussions, videos and observation of procedures with clinic patients who had consented to this. (This worked well, but no IUDs were fitted that day)

Slide presentation and brainstorming on ways to make SRH services more accessible to teenagers.

After an introduction by a health promotion worker, groups of three to four trainees spent 30 min preparing health promotion talks for the rest of the group who role played the target audiences

MCQ, multiple choice question; MEC, medical eligibility criteria; SRH, sexual and reproductive health. 


\section{DISCUSSION}

This paper reports on in-service training in family planning at one hospital in south-west Uganda. The hospital board had previously set the ambitious target of halving unmet need for family planning, estimated to affect $40 \%$ of women locally and saw the training as an important step towards this goal. All staff were offered basic training (level 1), which took place within time designated for staff development. The level 2 training required most attendees to use their free time, although the hospital modified rotas to ensure that service provision was not compromised. Despite this, enthusiasm for training was such that it had to be repeated. Monitoring of service usage is ongoing but it is too early to know whether this training has led to genuine improvements in patient care.

We were surprised by how confident the trainees said they were in the pre-course assessment, because it appeared that many had superficial knowledge and exaggerated fears of side effects. Some voiced negative attitudes during the session, exploring myths and adverse effects. This suggests that some of their initial confidence was misplaced, based on folk knowledge, rather than them being equipped to provide sound advice about modern contraceptive methods. This reinforced the importance of the training.

\section{Implications for course design}

Whilst other family planning courses are available, most take staff away from their work for 2-4 weeks, which limits the numbers from each service that can attend. Instead we adopted a 'whole-site' approach to training, which Bradley et $a l^{15}$ have also advocated and believe this may have prompted more change to service delivery.

By adapting freely available WHO materials, our course provided brief training that was culturally and clinically appropriate for the in-service context in Uganda, at minimal cost. Delivering this at the workplace allowed more to be trained, avoided compromising patient care and facilitated access to patients. The evaluation highlighted the value of combining a variety of teaching methods, which helped to sustain trainees' interest.

Traditionally training in Uganda has been rewarded with a 'per diem', a personal payment to cover a trainee's transport and provisions. This was not available to our trainees and although a few were disappointed, most accepted this and were motivated by group spirit, good refreshments and the course certificate.

One way to enhance training, when limited time is available, is to encourage pre-course learning. Although we suggested that participants use e-learning resources before the course, in the event few did, despite the availability of an internet connection. Trainees said this was because they did not have computers themselves, or time to access these on hospital machines. Emphasising the importance of pre-course learning, and downloading resources to the hospital network were proposed as ways to encourage this in the future, although just reading these as PDF files might be less interactive than working online.

\section{Implications for services}

We coined the term 'in-reach' to describe work to identify existing service users (patients and their relatives) who had unmet needs for family planning, contrasting this with outreach initiatives to the wider community. Ironically, this turned out not to be original, with Lynham et $a l^{16}$ reporting a similar initiative in Kenya in 1994. Another project, the Uganda Improvement Collaborative, demonstrated changes in clinic practice but little impact on postpartum family planning uptake. They identified a need to persuade women to accept family planning during the antenatal period and to train more staff to provide family planning. ${ }^{17}$ Both these initiatives highlight the importance of raising family planning proactively, and that this requires support across the whole healthcare facility.

Course participants felt less confident in their family planning discussions with men, yet it is clear that in sub-Saharan Africa men play a central role in decisions on family size, ${ }^{18}$ and there are many cultural beliefs, misconceptions and suspicions which make husbands sceptical about family planning. ${ }^{5}$ Suggestions to address this included taking services and health promotion to places where men gather, and encouraging men to attend healthcare consultations with their partners so that they can be involved in discussions about contraception.

Training also plays an important role in developing the morale and career prospects of health workers; indeed poor post-graduate training opportunities have been identified as a reason people are reluctant to work in primary care in sub-Saharan Africa (alongside the often poor working environment and difficult living conditions). ${ }^{19}$ Better training can therefore be expected to improve the status, recruitment and retention of staff.

\section{Making training widely available}

Our materials are freely available from the authors, or via the Training Resource Package. ${ }^{12}$ We are working to standardise the quality of teaching and assessment and secure external accreditation. Whereas in the UK, the Faculty of Sexual and Reproductive Health operates as a national organisation to promote excellence in family planning, there is no comparable organisation in Uganda. Making accredited training available more widely might facilitate the formation of such a grouping, and our work suggests that in-service training has the capacity to galvanise staff at a local level. Perhaps there could be an initiative to endorse 'family friendly' healthcare facilities to promote family planning, in the way that the 'Baby Friendly Initiative' promotes breastfeeding. ${ }^{20}$ 
The Ugandan Ministry of Health is preparing a revised curriculum for family planning, and the authors have contributed to discussions about a proposed national course. Building on this work, the UK Department for International Development has provided funding to a partnership between the Royal College of General Practitioners and Bwindi Community Hospital to develop this project, now named U-SHAPE (Uganda Sexual Health and Pastoral Education), replicating the training at Kisiizi Hospital and other institutions to test its generalisability.

Our approach appears to work well within the context of an effective not-for-profit community hospital and is stimulating discussion on how services can better reach patients needing contraception. It has led to the adoption of screening for unmet need, encouraging staff to consider family planning in every health encounter. Implementation may however be harder in government facilities, some of which face difficulties with low morale, inadequate staffing levels and a lack of protected time for professional development.

\section{CONCLUSIONS}

This model of in-service training offers a way to improve the confidence and knowledge of Ugandan health workers in providing family planning, and appeared to improve services across the hospital. Further work is needed to test this in other settings, ideally in a randomised trial, because our essentially descriptive evaluation does not provide definite evidence of impact. It does however appear that closely linking training to service delivery can empower health workers to extend both the reach and quality of family planning services.

Acknowledgements We thank the organisations who provided training resources, particularly WHO and Johns Hopkins University. We thank the Bwindi Community Hospital Staff who engaged so enthusiastically, Dr Rowena Neville who helped facilitate the second level 2 course and Sarah Uwimbabazi, Family Planning Coordinator at BCH, who contributed to each course and continues to provide training.

Funding We are grateful to the Royal College of General Practitioners Eric Gambrill Travelling Fellowship (Clare Goodhart) and the Scottish Episcopal Church (Sarah Capewell). Addenbrookes Abroad and Cambridgeshire Reproductive Health Training funded additional course expenses. The funders had no other involvement in the study.

\section{Competing interests None declared.}

Ethics approval Permission to undertake this work was given by the Executive Board, Bwindi Community Hospital who agreed that as no patient data were collected further ethical approval was not required. Staff participation was voluntary and they could withdraw at any stage.

Provenance and peer review Not commissioned; externally peer reviewed.

Data sharing statement Course materials are available from the corresponding author.

\section{REFERENCES}

1 United Nations DoEaSAPD. World Population Prospects: The 2012 Revision, Highlights and Advance Tables. Working Paper
No. ESA/P/WP.228. New York, UN: DESA, 2013:1-118. http:// esa.un.org/wpp/Documentation/pdf/WPP2012_HIGHLIGHTS. pdf [Accessed 20 May 2015].

2 Uganda Bureau of Statistics (UBOS), ICF International Inc. Uganda Demographic and Health Survey 2011. Kampala, Uganda: UBOS and Calverton, Maryland: ICF International Inc, 2012:1-244. http://www.ubos.org/onlinefiles/uploads/ubos/ UDHS/UDHS2011.pdf [Accessed 20 May 2015].

3 Graffy J, Goodhart C, Sennett K, et al. Young people's perspectives on the adoption of preventive measures for HIV/ AIDS, malaria and family planning in south-west Uganda: focus group study. BMC Public Health 2012;12:1022.

4 Nalwadda G, Mirembe F, Byamugisha J, et al. Persistent high fertility in Uganda: young people recount obstacles and enabling factors to use of contraceptives. BMC Public Health 2010;10:530.

5 Kaida A, Kipp W, Hessel P, et al. Male participation in family planning: results from a qualitative study in Mpigi district, Uganda. J Biosoc Sci 2005;37:269-286.

6 Ministry of Health. Uganda Clinical Guidelines. 2nd edn. Kampala: Ministry of Health, Republic of Uganda, 2010. http://www.health.go.ug/docs/ucg_2010.pdf [Accessed 20 May 2015].

7 Ministry of Health. Uganda Reproductive Health Commodity Security Strategic Plan 2010/11-2014/15. Kampala:

Government of Uganda, 2009. http://www.health.go.ug/docs/ HSSP_III_2010.pdf [Accessed 20 May 2015].

8 Mills A. Mass campaigns versus general health services: what have we learnt in 40 years about vertical versus horizontal approaches? Bull World Health Organ 2005;83: 315-316.

9 Dudley L, Garner P. Strategies for integrating primary health services in low- and middle-income countries at the point of delivery. Cochrane Database Syst Rev 2011;(7): CD003318.

10 Magtymova A. Strategies for integrating primary health services in middle- and low-income countries at the point of delivery: RHL commentary (last revised: 25 September 2007). The WHO Reproductive Health Library. Geneva: World Health Organization, 2007. http://apps.who.int/rhl/effective_practice_ and_organizing_care/amcom/en/ [Accessed 20 May 2015].

11 Nalwadda G, Mirembe F, Tumwesigye NM, et al. Constraints and prospects for contraceptive service provision to young people in Uganda: providers' perspectives. BMC Health Serv Res 2011;11:220.

12 Training Resource Package for Family Planning. 7-4-2014. Johns Hopkins University Management Sciences for Health and Pathfinder International. http://www.fptraining.org/about [Accessed 20 May 2015].

13 WHO Department of Reproductive Health \& Research and Johns Hopkins Bloomberg School of Public Health Knowledge for Health Project. Family Planning: A Global Handbook for Providers (2011 update). Baltimore; Geneva: CCP and WHO, 2011. http://www.fphandbook.org/ [Accessed 20 May 2015].

14 Family Planning: Blended Learning Module for the Health Extension Programme. Ethiopian Federal Ministry of Health and Open University (UK). 2013. http://labspace.open.ac.uk/ course/view.php?id=6720 [Accessed 20 May 2015].

15 Bradley J, Lynham PJ, Dwyer JC, et al. Whole-site Training: A New Approach to the Organization of Training. New York: AVSC International, 1998. http://www.engenderhealth.org/ pubs/workpap/wp11/wp_11.html\#top [Accessed 20 May 2015]. 


\section{Research}

16 Lynham PJ, Dwyer JC, Bradley J. Inreach: Reaching Potential Family Planning Clients within Health Institutions. AVSC

Working Paper. New York: ACSC International. 1994:5. http:// www.engenderhealth.org/pubs/workpap/wp5/wp_5.html [Accessed 20 May 2015].

17 Bitar S, Lamborne M. Uganda Improvement Collaborative: Integration of Family Planning into Maternal and Neonatal Health Programming. Washington DC: Evidence to Action Project, 2015:1-15. https://www.msh.org/sites/msh.org/files/ uganda-improvement-collaborative-brief.pdf [Accessed 20 May 2015].

18 Kim YM, Marangwanda C, Kols A. Involving Men in Family Planning: The Zimbabwe Male Motivation and Family
Planning Method Expansion Project, 1993-1994. IEC Field Report No 3. Baltimore, Maryland: Johns Hopkins School of Public Health, Center for Communication Programs, 1996. http://www.popline.org/node/294449 [Accessed 20 May 2015].

19 Moosa S, Wojczewski S, Hoffmann K, et al. Why there is an inverse primary-care law in Africa. Lancet Global Health 2013;1:e332-e333.

20 World Health Organisation / UNICEF. Protecting, Promoting and Supporting Breast-feeding: the Special Role of Maternity Services. Geneva: W.H.O., 1989. http://www.who.int/nutrition/ publications/infantfeeding/9241561300/en/ [Accessed 20 May 2015]. 